\title{
Impact of an innovative tuberculosis financing and payment model on health service utilization by tuberculosis patients in China: do the poor fare better than the rich?
}

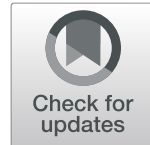

\author{
Di Dong ${ }^{1}$, Wei-Xi Jiang ${ }^{1}$, Qian Long ${ }^{1}$, Fei Huang ${ }^{2}$, Hui Zhang ${ }^{2}$, Jia-Ying Chen ${ }^{3}$, Li Xiang ${ }^{4}$, Qiang Li ${ }^{5}$, \\ Sheng-Lan Tang ${ }^{6 *}$ and Henry Lucas ${ }^{7}$
}

\begin{abstract}
Background: Tuberculosis (TB) prevalence is closely associated with poverty in China, and poor patients face more barriers to treatment. Using an insurance-based approach, the China-Gates TB program Phase II was implemented between 2012 and 2014 in three cities in China to improve access to TB care and reduce the financial burden on patients, particularly among the poor. This study aims to assess the program effects on service use, and its equity impact across different income groups.

Methods: Data from 788 and 775 patients at baseline and final evaluation were available for analysis respectively. Inpatient and outpatient service utilization, treatment adherence, and patient satisfaction were assessed before and after the program, across different income groups (extreme poverty, moderate poverty and non-poverty), and in various program cities, using descriptive statistics and multi-variate regression models. Key stakeholder interviews were conducted to qualitatively evaluate program implementation and impacts.

Results: After program implementation, the hospital admission rate increased more for the extreme poverty group (48.5 to $70.7 \%$ ) and moderate poverty group (45.0 to 68.1\%), compared to the non-poverty group (52.9 to 64.3\%). The largest increase in the number of outpatient visits was also for the extreme poverty group (4.6 to 5.7). The proportion of patients with good medication adherence increased by 15 percentage points in the extreme poverty group and by ten percentage points in the other groups. Satisfaction rates were high in all groups. Qualitative feedback from stakeholders also suggested that increased reimbursement rates, easier reimbursement procedures, and allowance improved patients' service utilization. Implementation of case-based payment made service provision more compliant to clinical pathways.
\end{abstract}

Conclusion: Patients in extreme or moderate poverty benefited more from the program compared to a non-poverty group, indicating improved equity in TB service access. The pro-poor design of the program provides important lessons to other TB programs in China and other countries to better address TB care for the poor.

Keywords: Health service use, Tuberculosis, Financing and payment model, Case-based payment

\footnotetext{
* Correspondence: zhanghui@chinacdc.cn; shenglan.tang@duke.edu

${ }^{2}$ National Center for Tuberculosis Control and Prevention, China CDC, Beijing, China

${ }^{6}$ Duke Global Health Institute, Duke University, Durham, NC, USA

Full list of author information is available at the end of the article
}

(c) The Author(s). 2019 Open Access This article is distributed under the terms of the Creative Commons Attribution 4.0 International License (http://creativecommons.org/licenses/by/4.0/), which permits unrestricted use, distribution, and reproduction in any medium, provided you give appropriate credit to the original author(s) and the source, provide a link to the Creative Commons license, and indicate if changes were made. The Creative Commons Public Domain Dedication waiver (http://creativecommons.org/publicdomain/zero/1.0/) applies to the data made available in this article, unless otherwise stated. 


\section{Multilingual abstracts}

Please see Additional file 1 for translations of the abstract into the five official working languages of the United Nations.

\section{Background}

Tuberculosis (TB) prevalence is closely associated with poverty in China. The 2010 National Tuberculosis Prevalence Survey shows that TB prevalence is much higher in rural areas than urban areas (163 vs 73 per $100000)$, and higher in the less developed western region than the developed eastern region (212 vs 66 per 100000 ) [1]. Some $83 \%$ of TB patients live in households with incomes below the regional median, and the average per capita household income of rural TB patients is $50 \%$ less than the local regional median [2].

Low-income TB patients in China face greater financial barriers to quality treatment and have lower treatment adherence $[3,4]$. Currently, TB treatment guidelines by the World Health Organization (WHO) and Chinese Center for Disease Control and Prevention (China CDC) recommend that rifampicin-sensitive newly diagnosed TB patients should receive 6 months of outpatient treatment and relapse TB patients 8 months [5-7]. A national survey in 2010 indicated that $10 \%$ of TB patients had intermittent treatment, and another $22 \%$ terminated before completing treatment. $15 \%$ of patients who terminated treatment reported that financial difficulties were the cause for their poor adherence [1]. TB patients with lower household incomes and education levels were more likely to report non-compliance [3]. Since 1990s, first-line anti-TB drugs and basic diagnostic tests during the standard treatment course are provided free of charge [8]. However, the overall cost of TB treatment is substantial, and poor TB patients are more likely to have catastrophic health expenditure. A study in three cities in China found that over $94 \%$ of households in the poorest quintile, compared to $43 \%$ in the richest quintile, had catastrophic expenditure due to TB treatment [4].

Several factors add to the financial barriers for poor patients to access TB treatment. First, many poor patients are covered by the New Rural Cooperative Medical Scheme (NCMS) or Urban Resident Basic Medical Insurance (URBMI), which have less comprehensive coverage and lower reimbursement rates for TB services compared to the Urban Employee Basic Medical Insurance (UEBMI) [9]. Second, low-income rural TB patients more often go to smaller regional hospitals that have a lower capacity to diagnose and treat complex cases. This may lead to over-provision of unnecessary and often expensive services not covered by the government free treatment policy or health insurance, such as computed tomography (CT) scans, branded second-line anti-TB drugs, liver protection and other ancillary drugs, the cost of which may further deter poor patients from completing treatment [10]. In addition, many poor patients live in rural and remote areas. Seeking treatment may therefore require travelling a considerable distance, incurring substantial transportation and accommodation costs [10] and possible loss of income.

To improve access to TB care and reduce the financial burden, particularly in rural areas, the China-Gates TB program Phase II was implemented between 2012 and 2014 in three prefectures from eastern (Zhenjiang), central (Yichang) and western (Hanzhong) China. The program context and intervention details have been documented elsewhere [8]. Briefly, the new TB financing and payment model includes: 1) increasing health insurance reimburse rates for hospitalization and outpatient $\mathrm{TB}$ services to $70 \%$; 2) changing the provider payment method to casebased payment from the current fee-for-service, to incentivize cost containment by TB-designated hospitals. For practical reasons, the case-based payment design included distinct payment packages for inpatient and outpatient services; 3) providing transportation and subsistence allowances to TB patients who adhered to treatment (including those without health insurance). Equity assessment at study baseline revealed that rural residents in project counties had less service utilization, but more out-of-pocket payment per hospital admission compared to urban employees and urban residents [11]. Analysis of the rural TB patients enrolled in the NCMS also revealed low reimbursement rate and high financial risk [12]. Service access and financial risk protection for TB patients with lower socioeconomic status were identified as major gaps in TB care [8].

There is rich international literature suggesting that public subsidies for health programs frequently benefit richer more than poorer people [13, 14]. Whether a health insurance-based approach can effectively target the poor and improve equity is therefore of great concern. This study aims to address this issue by considering the impact of the China-Gates TB program (Phase II) on service utilization, treatment adherence and patient satisfaction across three income groups identified as consisting of those living in: extreme poverty, moderate poverty and non-poverty.

\section{Methods}

\section{Study setting}

Quantitative data were obtained from cross-sectional surveys with $\mathrm{TB}$ patients at the baseline of the program in 2012 and final evaluation in 2014. Three counties (one low-income, one middle-income and one high-income) were selected in each of the three project prefectures (Zhenjiang, Yichang and Hanzhong). In each of the above 9 counties, TB patients who had been diagnosed for more than 6 months ( 8 months for relapse patients) were identified from the China CDC's TB information management 
system (TBIMS), which is a national registry for the compulsory reporting and management of confirmed TB cases. Ninety TB patients were randomly sampled from each of the nine counties' TBIMS. When less than 90 patients were present in a county, all patients were sampled. One of the county was excluded from analysis due to an unexpected restructuring of regional TB management system, leading to incomparable data at baseline and final evaluation. Face-to-face interviews were conducted using a structured questionnaire, which included information on patient socio-economic background, treatment history, and satisfaction. A total of 788 patient questionnaires were analysed from the baseline survey and 775 from the final evaluation survey.

\section{Income grouping and poverty status}

The self-reported per capita annual income of a patient's household was used for income grouping. Following the World Bank's definition of extreme poverty globally and the poverty line for upper-middle income countries, those with incomes less than USD 1.9 a day (RMB 4369 per annum) were classified as being in extreme poverty, those with incomes between USD 1.9 to 5.5 a day (RMB 12647 per annual) were classified as being in moderate poverty, and the rest were classified as non-poverty households [15]. This classification was validated to be relevant to local poverty standards in Zhenjiang, Yichang and Hanzhong. The local living assistance standards for urban residents announced by the Department of Civil Affairs all three cities in 2014 were similar to or higher than the World Bank standard of extreme poverty.

\section{Measuring service utilization, adherence, and patient's satisfaction}

Inpatient and outpatient service utilization indicators were analysed, including the hospital admission rate, average number of hospital admissions per patient, rate of hospital re-admission within 3 days of discharge, average length of stay for the first admission, and average number of outpatient visits during a treatment course ( 6 months for new patients, and 8 months for relapse patients). Medication adherence was characterized using the following indicators: proportion of patients refusing treatment, taking medications as prescribed, and terminating treatment. Patient satisfaction was measured relating to: treatment outcome, reimbursement rate, reimbursement procedures, attitudes of doctors and nurses.

\section{Statistical analysis}

Utilization of inpatient and outpatient services, patient adherence and satisfaction were examined for each poverty status at baseline and at final evaluation using descriptive statistics.
The effect of the program on the rate of hospital admission, rate of re-admission within 3 days after discharge, and proportion of patients with good medication adherence were analysed using multivariate logistic regression model. Number of outpatient visits over the whole treatment course were analysed using Poisson regression. All regression models included the following explanatory variables: period (baseline, final evaluation), poverty status and the interaction term between poverty status and period as explanatory variables. All models were controlled for county fixed effects and clusterrobust standard errors were used for statistical testing. A set of control variables were included in all regression models, including gender, age, marital status, TB type (new, relapse), education level, employment status and health insurance type. The models estimated were thus of the form:

Outcome $=f$ (poverty status, period, poverty status"period, control variables, county fixed effect).

All analyses were performed using Stata 14 (Version 14, StataCorp, College Station, TX. Statistical significance were assessed at $P=0.05$.

\section{Qualitative interviews and analyses}

Qualitative data were obtained during the final evaluation period of the program in 2014. Semi-structured in-depth interviews were conducted with city- and county-level health administrators $(n=12)$, health insurance managers $(n=20)$ and hospital managers $(n=12)$ to understand their perceptions of the program impacts on poor TB patients' service utilization and equity. Two focus group discussions (FGDs) were held with healthcare providers in TB designated hospital and primary care doctors in each study county to explore their views of the program impacts on service provision and patient adherence. Each group consisted of 5-6 physicians and nurses who provided outpatient and/or inpatient $\mathrm{TB}$ care and were responsible for $\mathrm{TB}$ patient management. In addition, two FGDs with TB patients were organized in each study county to gain understandings of patients' care seeking and treatment experiences and level of satisfaction. TB patients were quota sampled based on their gender, household income and type of health insurance coverage. Each group consisted of 6 TB patients and was held in a private room in the hospital. All interviews were conducted by experienced evaluation team members and recorded after obtaining the permission of participants.

The Framework approach [16] was used to analyse the qualitative data. A framework constructed using the topic guide, field notes and categories emerging from the transcripts, was applied to the data to identify themes. Data from different stakeholders and other sources were triangulated. The key findings were also validated by external consultation. 


\section{Results}

A total of 788 patient questionnaires were analysed from the baseline survey and 775 from the final evaluation survey. The socio-economic characteristics of patients were similar in both samples, except for their health insurance coverage (Table 1). At baseline, $34 \%$ of patients were classified as in extreme poverty and $42 \%$ in moderate poverty compared to 36 and $40 \%$ at final evaluation.

After program implementation, utilization of inpatient and outpatient services increased, but to different extents

Table 1 Characteristics of TB patients at baseline and final evaluation

\begin{tabular}{|c|c|c|c|}
\hline Sample Characteristics & $\begin{array}{l}\text { Baseline } \\
(n=788)\end{array}$ & $\begin{array}{l}\text { Final evaluation } \\
(n=775)\end{array}$ & $P$ value \\
\hline \multicolumn{4}{|l|}{ Gender (\%) } \\
\hline Male & 74.8 & 70.7 & 0.070 \\
\hline \multicolumn{4}{|l|}{ Age (\%) } \\
\hline$<30$ & 6.2 & 7.4 & \multirow[t]{3}{*}{0.070} \\
\hline $30-59$ & 46.7 & 41.0 & \\
\hline$\geq 60$ & 47.1 & 51.6 & \\
\hline \multicolumn{4}{|l|}{ Marriage (\%) } \\
\hline Married & 80.3 & 78.2 & 0.290 \\
\hline \multicolumn{4}{|l|}{ Residence (\%) } \\
\hline Rural & 92.5 & 90.0 & 0.083 \\
\hline \multicolumn{4}{|l|}{ Patient category (\%) } \\
\hline New patient & 81.4 & 82.2 & 0.670 \\
\hline \multicolumn{4}{|l|}{ Education level (\%) } \\
\hline None & 20.2 & 25.0 & \multirow[t]{4}{*}{0.052} \\
\hline Primary & 32.9 & 33.6 & \\
\hline Secondary & 34.0 & 28.7 & \\
\hline High school and above & 12.9 & 12.8 & \\
\hline \multicolumn{4}{|l|}{ Insurance type (\%) } \\
\hline UEBMI & 6.4 & 9.3 & \multirow[t]{7}{*}{0.000} \\
\hline URBMI & 2.8 & 3.2 & \\
\hline NCMS & 87.8 & 82.2 & \\
\hline URRBMI & 0.0 & 2.5 & \\
\hline Private insurance & 1.8 & 0.4 & \\
\hline other insurance & 0.3 & 0.3 & \\
\hline no insurance & 1.0 & 2.2 & \\
\hline \multicolumn{4}{|l|}{ Employment (\%) } \\
\hline $\begin{array}{l}\text { Currently working (including } \\
\text { farming) }\end{array}$ & 53.3 & 49.0 & 0.092 \\
\hline \multicolumn{4}{|l|}{ Income level (\%) } \\
\hline Extreme poverty & 34.0 & 36.1 & \multirow[t]{3}{*}{0.642} \\
\hline Moderate poverty & 42.0 & 40.0 & \\
\hline Non-poverty & 24.0 & 23.9 & \\
\hline
\end{tabular}

UEBMI Urban employee basic medical insurance, URBMI Urban resident basic medical insurance, NCMS New corporative medical scheme, URRBMI Urban rural resident basic medical insurance in different poverty groups. The hospital admission rate increased from 48.1 to $68.1 \%$ among all patients, and the increase was greater for the extreme poverty and moderate poverty groups (Table 2 ). The average number of hospital admissions decreased from 1.4 to 1.2, and the rate of re-admissions decreased from 23.0 to $15.5 \%$. The length of stay for the first hospital admission increased in the extreme and moderate poverty groups, but decreased in the non-poverty group. The number of outpatient visits increased from 4.8 to 5.7 among all patients, and the increase was highest in the extreme poverty group.

After program implementation, medication adherence improved the most in the extreme poverty group (Table 3). The proportion of patients refusing treatment decreased in the extreme poverty and non-poverty groups, but not in the moderate poverty group. The proportion of patients taking medication on schedule as prescribed increased by 15 percentage points in the extreme poverty group, and 10 percentage points in the other two groups. The proportion terminating treatment also decreased the most in the extreme poverty group, followed by the moderate poverty group.

Over $90 \%$ of patients reported satisfaction with treatment outcome, procedure, and the attitudes of doctors and nurses in both baseline and final evaluation surveys, and the proportion satisfied were slightly higher at final evaluation compared to baseline (Table 3). Reimbursement rates were satisfactory to the smallest proportion of patients but were still seen as acceptable to around $87 \%$ before and $90 \%$ after program implementation. The satisfaction did not seem to vary by poverty group.

The multivariate regression results are shown in Table 4. As expected, the overall hospitalization rate was substantially higher for members of the non-poverty group $(O R=1.44, P=0.05)$. However, while program implementation appears to have considerably increased the hospitalization rate for all income groups $(O R=2.83$, $P=0.01)$, the increase was much lower for the nonpoverty group $(O R=0.56, P=0.04)$, indicating increased equity of access. The re-admission rate did not seem to change after the program and there were no significant variations across poverty groups. The number of outpatient visits increased for all groups, and intra-group differences were not significant. The proportion of patients with good medication adherence improved significantly ( $O R=2.88, P=0.01)$, and there were again no significant differences across poverty groups. Patient satisfaction with treatment outcomes improved after the program but satisfaction with the reimbursement rate did not change.

The qualitative results support the quantitative findings on increased outpatient and inpatient TB service use, and allow identification of some of the underlying reasons. First, most health administrators, health insurance managers, 
Table 2 Inpatient and outpatient service utilization at baseline and final evaluation (by income group)

\begin{tabular}{|c|c|c|c|c|c|}
\hline Indicator & Period & Extreme poverty & Moderate poverty & Non-poverty & Total \\
\hline \multirow[t]{2}{*}{ Hospital admission rate (\%) } & Baseline & 48.5 & 45.0 & 52.9 & 48.1 \\
\hline & Final evaluation & 70.7 & 68.1 & 64.3 & 68.1 \\
\hline \multirow[t]{2}{*}{ Average number of hospital admissions } & Baseline & 1.5 & 1.3 & 1.3 & 1.4 \\
\hline & Final evaluation & 1.3 & 1.2 & 1.2 & 1.2 \\
\hline \multirow[t]{2}{*}{ Average rate of hospital re-admissions (\%) } & Baseline & 29.2 & 17.5 & 23.0 & 23.0 \\
\hline & Final evaluation & 21.2 & 11.9 & 12.6 & 15.5 \\
\hline \multirow{2}{*}{$\begin{array}{l}\text { Average length of stay of the first } \\
\text { admission (days) }\end{array}$} & Baseline & 21.1 & 22.6 & 26.1 & 23.0 \\
\hline & Final evaluation & 24.0 & 24.7 & 25.6 & 24.7 \\
\hline \multirow{2}{*}{$\begin{array}{l}\text { Average number of outpatient visits during } \\
\text { treatment course }\end{array}$} & Baseline & 4.6 & 5.0 & 4.8 & 4.8 \\
\hline & Final evaluation & 5.7 & 5.7 & 5.8 & 5.7 \\
\hline
\end{tabular}

${ }^{a}$ Only patients who had been diagnosed as TB for more than $6 / 8$ months at the time of survey were included for analysis of outpatient visits

hospital managers and TB care providers thought that the increased health insurance reimbursement rate for TB care and the simplified reimbursement procedure for patients had a positive impact on service use, particularly among poor TB patients. Several TB care providers explained that the reimbursement rate for TB outpatient care was low before the introduction of the program, for example, only $20 \%$ of eligible expenditure would be reimbursed by NCMS, as compared to $80 \%$ after program implementation. Most TB patients also expressed their satisfaction with the increased reimbursement rate. Second, hospital managers mentioned that an upgraded IT system for case-based payment allowed patients to receive insurance reimbursement at the time of bill payment. Previously, paying a substantial deposit at admission or paying out-of-pocket while receiving treatment placed a major burden on poor patients.
Some terminated treatment due to an inability to afford such payments even though a large proportion was expected to be reimbursed subsequently by insurance. Third, patients found transport and subsistence allowances provided effective motivation to undertake follow-up visits, especially for poor patients living in remote rural or mountainous areas. Travelling to a hospital could take many hours and entail significant costs, sometimes requiring an over-night stay. The allowances partially offset such costs, and disbursement of a lump sum payment upon completion incentivized treatment adherence.

The current direct exemption of reimbursable expenses (at time of bill payment upon discharge) is good for poor patient, and rich patients may not care. (TB hospital manager)

Table 3 Program effect on patients' treatment adherence and satisfaction

\begin{tabular}{|c|c|c|c|c|c|}
\hline Indicator & Period & Extreme poverty & Moderate poverty & Non-poverty & Total \\
\hline \multirow{2}{*}{$\begin{array}{l}\text { Proportion of patients who refused } \\
\text { treatment (\%) }\end{array}$} & Baseline & 4.9 & 2.4 & 2.7 & 3.3 \\
\hline & Final evaluation & 2.9 & 2.9 & 1.6 & 2.6 \\
\hline \multirow{2}{*}{$\begin{array}{l}\text { Proportion of patients taking medications } \\
\text { as prescribed (\%) }\end{array}$} & Baseline & 75.4 & 81.6 & 81.0 & 79.3 \\
\hline & Final evaluation & 90.5 & 93.1 & 92.3 & 92.0 \\
\hline \multirow{2}{*}{$\begin{array}{l}\text { Proportion of patients terminating } \\
\text { treatment (\%) }\end{array}$} & Baseline & 19.0 & 13.0 & 15.9 & 15.7 \\
\hline & Final evaluation & 5.9 & 4.9 & 6.0 & 5.5 \\
\hline \multirow{2}{*}{$\begin{array}{l}\text { Proportion of patients who satisfy with } \\
\text { the treatment outcome (\%) }\end{array}$} & Baseline & 94.7 & 92.1 & 93.1 & 93.2 \\
\hline & Final evaluation & 96.8 & 96.1 & 98.4 & 96.9 \\
\hline \multirow{2}{*}{$\begin{array}{l}\text { Proportion of patients who satisfy with } \\
\text { the reimbursement rate (\%) }\end{array}$} & Baseline & 86.2 & 86.9 & 88.3 & 87.0 \\
\hline & Final evaluation & 90.9 & 89.5 & 89.0 & 89.9 \\
\hline \multirow{2}{*}{$\begin{array}{l}\text { Proportion of patients who satisfy with } \\
\text { the reimbursement process (\%) }\end{array}$} & Baseline & 93.1 & 90.5 & 92.3 & 91.8 \\
\hline & Final evaluation & 93.3 & 90.6 & 93.3 & 92.3 \\
\hline \multirow{2}{*}{$\begin{array}{l}\text { Proportion of patients who satisfy with } \\
\text { doctor's attitude (\%) }\end{array}$} & Baseline & 96.1 & 96.6 & 99.0 & 97.1 \\
\hline & Final evaluation & 99.1 & 98.2 & 99.2 & 98.8 \\
\hline \multirow{2}{*}{$\begin{array}{l}\text { Proportion of patients who satisfy with } \\
\text { nurse's attitude (\%) }\end{array}$} & Baseline & 96.9 & 97.3 & 99.0 & 97.6 \\
\hline & Final evaluation & 99.1 & 97.8 & 98.4 & 98.4 \\
\hline
\end{tabular}


Table 4 Program effect for different income groups

\begin{tabular}{|c|c|c|c|c|c|c|c|c|c|c|}
\hline & \multicolumn{2}{|c|}{ Hospital admission } & \multicolumn{2}{|c|}{$\begin{array}{l}\text { Rate of } \\
\text { re-admission }\end{array}$} & \multicolumn{2}{|c|}{$\begin{array}{l}\text { Average number } \\
\text { of outpatient visits }\end{array}$} & \multicolumn{2}{|c|}{$\begin{array}{l}\text { Good medication } \\
\text { adherence }\end{array}$} & \multicolumn{2}{|c|}{$\begin{array}{l}\text { Satisfaction with } \\
\text { treatment outcomes }\end{array}$} \\
\hline & Odds ratio & $P$ value & Odds ratio & $P$ value & Coefficient & $P$ value & Odds ratio & $P$ value & Odds ratio & $P$ value \\
\hline \multicolumn{11}{|l|}{$\begin{array}{l}\text { Poverty status (Moderate poverty as } \\
\text { reference group) }\end{array}$} \\
\hline Extreme poverty & 1.1 & 0.7 & 2.2 & 0.06 & -0.1 & 0.21 & 0.7 & 0.23 & 1.5 & 0.07 \\
\hline Non-poverty & 1.4 & 0.05 & 1.5 & 0.08 & -0.1 & 0.27 & 0.9 & 0.55 & 1.3 & 0.48 \\
\hline \multicolumn{11}{|l|}{ Period (baseline as reference group) } \\
\hline Final evaluation & 2.8 & 0.01 & 0.6 & 0.11 & 0.1 & 0.01 & 2.9 & 0.01 & 2.0 & 0.04 \\
\hline \multicolumn{11}{|l|}{ Income level* Period } \\
\hline Extreme poverty *Final evaluation & 1.0 & 0.98 & 1.1 & 0.9 & 0.1 & 0.16 & 1.1 & 0.88 & 0.7 & 0.44 \\
\hline Non-poverty *Final evaluation & 0.6 & 0.01 & 0.8 & 0.46 & 0.1 & 0.16 & 0.9 & 0.72 & 2.6 & 0.16 \\
\hline \multicolumn{11}{|l|}{ Gender (male as reference group) } \\
\hline Female & 0.7 & 0.01 & 1.2 & 0.46 & 0.0 & 0.28 & 1.1 & 0.62 & 1.5 & 0.16 \\
\hline \multicolumn{11}{|l|}{ Age group (<30 as reference group) } \\
\hline $30-59$ & 0.9 & 0.82 & 2.7 & 0.01 & 0.0 & 0.46 & 0.9 & 0.68 & 0.8 & 0.58 \\
\hline $60+$ & 1.2 & 0.08 & 1.0 & 0.83 & 0.0 & 0.89 & 1.0 & 0.83 & 1.9 & 0.08 \\
\hline \multicolumn{11}{|l|}{$\begin{array}{l}\text { Type of TB (newly diagnosed as } \\
\text { reference group) }\end{array}$} \\
\hline Relapse & 1.0 & 0.76 & 1.2 & 0.49 & -0.1 & 0.14 & 0.6 & 0.01 & 0.5 & 0 \\
\hline \multicolumn{11}{|l|}{ Marital status (single as reference group) } \\
\hline Married & 1.0 & 0.89 & 1.2 & 0.52 & 0.1 & 0.23 & 1.1 & 0.56 & 0.8 & 0.57 \\
\hline \multicolumn{11}{|l|}{$\begin{array}{l}\text { Education (no formal education as } \\
\text { reference group) }\end{array}$} \\
\hline Primary & 1.0 & 0.68 & 0.9 & 0.68 & 0.0 & 0.30 & 1.0 & 0.97 & 1.0 & 0.95 \\
\hline Secondary & 1.1 & 0.67 & 1.2 & 0.46 & 0.1 & 0.21 & 1.2 & 0.52 & 1.1 & 0.87 \\
\hline$\geq$ High school & 1.0 & 0.84 & 1.2 & 0.64 & 0.1 & 0.16 & 2.1 & 0.01 & 0.5 & 0.04 \\
\hline \multicolumn{11}{|l|}{ Insurance type } \\
\hline UEBMI & 0.4 & 0.04 & 1.0 & 0.96 & 0.0 & 0.86 & 1.6 & 0.17 & 0.5 & 0.35 \\
\hline NCMS & 0.4 & 0.01 & 1.3 & 0.46 & 0.0 & 0.64 & 1.4 & 0.38 & 0.8 & 0.82 \\
\hline URRBMI & 0.3 & 0 & 1.4 & 0.65 & 0.1 & 0.06 & 1.9 & 0.59 & & \\
\hline Private & 1.1 & 0.91 & & & 0.0 & 0.84 & 0.7 & 0.52 & & \\
\hline No insurance & 0.4 & 0.06 & 0.3 & 0.07 & -0.1 & 0.70 & 1.3 & 0.46 & 0.8 & 0.85 \\
\hline Other insurance & 0.9 & 0.96 & 1.8 & 0.69 & 0.4 & 0.01 & 0.6 & 0.59 & & \\
\hline $\begin{array}{l}\text { Currently working (currently no } \\
\text { working as reference group) }\end{array}$ & 0.6 & 0 & 0.9 & 0.57 & 0.0 & 0.95 & 0.8 & 0.33 & 1.3 & 0.38 \\
\hline
\end{tabular}

UEBMI Urban employee basic medical insurance, URBMI Urban resident basic medical insurance, NCMS New corporative medical scheme, URRBMI Urban rural resident basic medical insurance

I received $R M B 180$ for transportation and nutrition allowance. It helps me. Maybe you (policy maker) can consider giving more for those who live far away. (TB patient, FGD)

Some hospital managers and providers considered the design of the health insurance reimbursement package to be in line with the standard TB clinical treatment pathway, which to some extent improved quality of TB care and case management. Several providers said that after program implementation, they prescribed TB treatment-related tests according to the clinical guideline and strengthened coordination with primary healthcare providers to follow up TB patients and encourage them to attend scheduled hospital visits. In FGDs with TB patients, many patients said they had frequent contacts with healthcare providers.

Before the program, we only did some of the tests (like liver function test, blood test, kidney function) 
occasionally. After patients are discharged, we didn't follow them anymore. Now, there is emphasis on standard treatment and quality, so we have improved on tests. Those necessary tests are done every month. If patients have adverse reactions, they can receive timely treatment. (TB doctor, FGD)

Now after a patient leave the hospital, we inform the village doctor to supervise the patient, and call the patient every month to remind him/her of the followup visit. (TB doctor, FGD)

\section{Discussion}

Overall, the China-Gates TB program Phase II has improved inpatient and outpatient TB care access, reduced re-admissions, enhanced medication adherence, and improved patient's satisfaction with treatment outcomes. It was also found to be pro-poor and to have improved equity in inpatient TB care access across different poverty groups: the program effects on hospital admissions were greater for the extreme poverty and moderate poverty groups, compared to the non-poor group. Program effects on outpatient service utilization were similar across different groups, and number of outpatient visit did not correlate with poverty status.

One commonly suggested potential adverse consequence of case-based payment is that facilities may underprovide necessary services to control costs [17-19]. On the contrary, the increased number of outpatient visits observed in this study and qualitative findings from the study suggest that patients were in fact better managed, i.e. more in line with established clinical guidelines. This was probably mainly because the payment standard for the outpatient package was generous in terms of covering the full cost of services and drugs recommended by the clinical treatment guideline.

While the reduced gap in terms of inpatient service use between poor and non-poor TB patients indicates improved equity, it remains difficult to assess with existing data if the high levels of hospitalization following the intervention implementation represent an improvement in service provision, as a majority of TB patients may only require outpatient treatment according to global and national treatment guidelines. The original case-based payment design was a standard payment rate for inpatient and outpatient TB services combined, aiming to promote substitution of hospitalization by outpatient treatments and to avoid unnecessary hospitalization. However, during the program implementation, significant challenges were encountered from hospitals and health insurance agencies in program regions due to expected reduction in revenue, and difficulty in management. As a result, two payment packages were implemented for inpatient and outpatient services separately, the design of which was unable to reduce hospitalization. The detailed implementation challenges and consequences were discussed in detail in another paper by the same study team. Nevertheless, the decreasing gap in inpatient service utilization between the extreme-poverty group and non-poverty group could have positive effects, as qualitative interviews revealed that many extreme-poverty patients were elderly patients and had several co-morbidities (such as diabetes, hypertension, and kidney diseases) or side effects from TB treatment. Better access to inpatient services may improve the management of complex TB cases with co-morbidities. Future studies are needed to access the health service quality and appropriateness, and treatment outcomes.

The pro-poor effects can be explained by several features. First, the program required reimbursement rates for all insurance schemes to be no less than $70 \%$ for covered inpatient and outpatient services. Before the program, there was wide variation in reimbursement rates by the three major health insurance schemes. NCMS and URBMI reimbursed $60-75 \%$ of inpatient expenses, whereas UEBMI reimbursed 85-95\% [11]. NCMS and URBMI had no or low reimbursement rates for outpatient expenses [11]. Poor TB patients usually enrol in NCMS and URBMI schemes which have lower reimbursement rates. The program reduced the disparity in reimbursement rates, thereby favouring the poor. Second, an upgraded IT system that allowed immediate insurance reimbursement was most beneficial for poorer patients, as they were not required to pay a large amount of cash at the point of service use, and then got a reimbursement later. Third, transport and subsistence allowances provided strong incentives to poor patients, many of whom live in remote rural areas and had higher transportation costs, to seek care. Fourth, medical financial assistance was provided by the Department of Civil Affairs for a relatively small number of eligible low-income households, further reducing their financial burden. Fifth, from the supply side, the implementation of case-based payment, clinical pathways, and case management probably improved the treatment and management quality more in under-developed areas, where many poor patients resided.

Despite great improvements in TB management, poor TB patients still face a number of barriers and challenges in accessing health care and completing treatment. Some TB services and drugs were excluded from insurance program reimbursement. For example, in many counties, CT scans, branded liver-protection drugs and ancillary drugs were not covered by insurance, nor restricted by the cost limit of case-based payment [6] Though case-based payment was designed to restrict the provision of unnecessary tests and drugs, their actual use was not uncommon. For instance, a significant 
proportion of patients reported having adverse reactions to free anti-TB drugs, and were therefore given more expensive second line drugs and in some cases were encouraged to take liver-protection drugs, or be admitted for inpatient care. In order to further reduce the financial barriers to care for poor TB patients, the types of services covered by insurance should be expanded, with appropriate safeguards to control unnecessary use of more expensive treatments.

The study was not without limitations. There was very limited quantitative information on patient case-mix and service details (such as prescriptions and procedures). Therefore, appropriateness and quality of services cannot be assessed objectively. Service quality can only be inferred from reported patient satisfaction and qualitative feedback from patients, doctors and administrators. Besides, the program consists of multiple concurrent interventions that may be synergistic or antagonistic, and thus the effects of each individual intervention cannot be evaluated separately.

\section{Conclusions}

The China-Gates TB program Phase II effectively improved TB patients' access to inpatient and outpatient services and improved medication adherence across all income groups. Patients in households classified as in extreme or moderate poverty benefited more from the inpatient service coverage of the program compared to a non-poverty group, indicating improved equity in inpatient TB service access. The pro-poor design of the program provides important lessons to other TB programs in China and other countries to better address TB care for the poor. The study also identified other difficulties poor TB patients face that need to be further addressed.

\section{Additional file}

Additional file 1: Multilingual abstracts in the five official working languages of the United Nations. (PDF $468 \mathrm{~kb}$ )

\begin{abstract}
Abbreviations
China CDC: Chinese Center for Disease Control and Prevention; CT: Computed tomography; FGD: Focus-group discussion; NCMS: New cooperative medical schemes; TB: Tuberculosis; TBIMS: Tuberculosis information management system; UEBMI: Urban employee basic medical insurance; URBMI: Urban resident basic medical insurance; WHO: World Health Organization
\end{abstract}

\section{Acknowledgements}

This paper, as part of the outputs emanating from the program entitled "China National Health and Family Planning Commission and the Gates Foundation TB Project (Phase II)" - a collaboration between the China Government and the Bill and Melinda Gates Foundation (Grant No. 51914), and implemented by the China Center of Disease Control and Prevention (CDC). The Duke Global Health Institute, Duke Kunshan University, Nanjing Medical University, Huazhong University of Science and Technology and Xi'an Jiaotong University were contracted by the Foundation and China CDC to undertake the baseline survey and the final evaluation to assess the impact of the comprehensive model of TB/MDRTB control and care in China. Dr. Xie-Xiu Wang, Dr. Shui-Gao Jin, Dr. Shi-Wen Jiang, the three senior advisors of the project, participated in part of the survey and provided very helpful technical supports to the project, to which the authors of the paper are immensely grateful. The authors of the paper would also express their sincere appreciation to Dr. Daniel Chin and Shi-Tong Huang from the Gates Foundation, You Li, Miao-Miao Sun from project management office at China CDC, Zhi-Ying Zhang from PATH, and other colleagues from China CDC at national, provincial, prefectural and county levels, as well as from TB designated hospitals at prefectural and county levels in the three project prefectures who generously contributed their time to the implementation of the study.

\section{Authors' contributions}

DD conducted literature search. SLT, DD, WXJ, JYC, LX, QL, FH and HZ designed the study, collected the data and interpreted the data, DD, QL, and WXJ conducted data analysis. DD prepared the manuscript; QL, HL, SLT, and WXJ revised the manuscript and provided valuable suggestions to improve the manuscript. All authors read and approved the final manuscript.

\section{Funding}

The whole study was funded by the Bill and Melinda Gates Foundation.

\section{Availability of data and materials}

The datasets generated and analysed during the current study are not publicly available due to the regulations of China CDC. Readers of the article need to discuss with China CDC and obtain their permission before the release of the dataset.

\section{Ethics approval and consent to participate}

Ethical approval of the study was issued by the Institutional Review Board of Chinese Center for Disease Control and Prevention. Consent form was obtained before individual data collection and could be provided upon request.

\section{Consent for publication}

Consent form was obtained before individual data collection and could be provided upon request.

\section{Competing interests}

All authors declare that they have no competing interests.

\section{Author details}

${ }^{1}$ Global Health Research Center, Duke Kunshan University, Kunshan, Jiangsu, China. ${ }^{2}$ National Center for Tuberculosis Control and Prevention, China CDC, Beijing, China. ${ }^{3}$ School of Policy and Management, Nanjing Medical University, Nanjing, Jiangsu, China. ${ }^{4}$ Tongji Medical College of Huazhong University of Science and Technology, Wuhan, Hubei, China. ${ }^{5}$ School of Public Health, Xi'an Jiaotong University, Xi'an, Shaanxi, China. ${ }^{6}$ Duke Global Health Institute, Duke University, Durham, NC, USA. ${ }^{7}$ Institute of Development Studies, University of Sussex, Brighton, UK.

Received: 16 October 2018 Accepted: 28 May 2019

Published online: 11 June 2019

\section{References}

1. Wang $L$, Zhang $H$, Ruan $Y$, Chin DP, Xia Y, Cheng S, et al. Tuberculosis prevalence in China, 1990-2010; a longitudinal analysis of national survey data. Lancet. 2014;383(9934):2057-64.

2. Wang L, Cheng S, Chen M. 2010 5th National Tuberculosis Epidemiological Survey Report. Chin J Antituberculosis. 2012;34(8):485-508.

3. Long Q, Smith H, Zhang T, Tang S, Garner P. Patient medical costs for tuberculosis treatment and impact on adherence in China: a systematic review. BMC Public Health. 2011;11(1):393.

4. Zhou C, Long Q, Chen J, Xiang L, Li Q, Tang S, et al. Factors that determine catastrophic expenditure for tuberculosis care: a patient survey in China. Infect Dis Poverty. 2016;5(1):6.

5. WHO, Initiative ST. Treatment of tuberculosis: quidelines: World Health Organization; 2010. 
6. MOH. TB outpatient diagnosis and treatment standard 2012. Available from: http://www.moh.gov.cn/cmsresources/mohyzs/cmsrsdocument/doc14054. doc. Accessed on June 7, 2018.

7. Prevention CCfDCa. China TB control and prevention plan implementation guide (2008 Edition) 2008. Available from: http://tb.chinacdc.cn/zcfg/sszn/ 201207/t20120711_64166.htm. Accessed on June 7, 2018

8. Tang S, Wang L, Wang H, Chin DP. Access to and affordability of healthcare for TB patients in China: issues and challenges. Infect Dis Poverty. 2016;5(1):10.

9. Yip WC-M, Hsiao WC, Chen W, Hu S, Ma J, Maynard A. Early appraisal of China's huge and complex health-care reforms. Lancet. 2012;379(9818):833-42.

10. Chen S, Zhang H, Pan Y, Long Q, Xiang L, Yao L, et al. Are free antituberculosis drugs enough? An empirical study from three cities in China. Infect Dis Poverty. 2015;4(1):47.

11. Pan $Y$, Chen $S$, Chen $M$, Zhang $P$, Long $Q$, Xiang L, et al. Disparity in reimbursement for tuberculosis care among different health insurance schemes: evidence from three counties in Central China. Infect Dis Poverty. 2016;5(1):7.

12. Xiang L, Pan $Y$, Hou S, Zhang $H$, Sato KD, Li Q, et al. The impact of the new cooperative medical scheme on financial burden of tuberculosis patients: evidence from six counties in China. Infect Dis Poverty. 2016;5(1):8.

13. Victora CG, Wagstaff A, Schellenberg JA, Gwatkin D, Claeson M, Habicht J-P. Applying an equity lens to child health and mortality: more of the same is not enough. Lancet. 2003;362(9379):233-41.

14. Castro-Leal F, Dayton J, Demery L, Mehra K. Public social spending in Africa: do the poor benefit? World Bank Res Obs. 1999;14(1):49-72.

15. WB. World Bank Poverty \& Equity Data Portal 2017. Available from: http:// povertydata.worldbank.org/poverty/country/CHN. Accessed on June 7, 2018.

16. Smith J, Firth J. Qualitative data analysis: the framework approach. Nurse Res. 2011;18(2):52-62.

17. WHO. Case-based Payment Systems for Hospital Funding in Asia An Investigation of Current Status and Future Directions: An Investigation of Current Status and Future Directions: OECD Publishing; 2015.

18. Langenbrunner J, Cashin C, O'Dougherty S. Designing and implementing health care provider payment systems: how-to manuals. Washington: World Bank Publications; 2009.

19. Busse R, Geissler A, Quentin W. Diagnosis-related groups in Europe: moving towards transparency, efficiency and quality in hospitals: McGraw-Hill Education (UK). p. 2011.

Ready to submit your research? Choose BMC and benefit from:

- fast, convenient online submission

- thorough peer review by experienced researchers in your field

- rapid publication on acceptance

- support for research data, including large and complex data types

- gold Open Access which fosters wider collaboration and increased citations

- maximum visibility for your research: over $100 \mathrm{M}$ website views per year

At $\mathrm{BMC}$, research is always in progress.

Learn more biomedcentral.com/submissions 